\title{
A Unified General Class of Interdistributional Income Inequality Measures Based on Weighted Incomplete Moments
}

\author{
Fahad Aldossary ${ }^{1}$, Abouelmagd, Tamer $^{2}$, A. A. E. Ahmed ${ }^{3}$ \\ ${ }^{1}$ Management Information System Department, Taibah University, Saudi Arabia \\ ${ }^{2}$ Department of Statistics, Mathematics and Insurance, Benha University, Egypt \\ ${ }^{3}$ Department of Statistics, Mathematics and Insurance, Helwan University, Egypt \\ Correspondence: Thomas C. Keane, Director, ISES Labs, Department of Chemistry and Biochemistry, Russell Sage \\ College, Troy, NY 12180, USA. Tel: 1-518-244-2299. E-mail: keanet@ sage.edu
}

Received: June 7, 2021 Accepted: September 29, $2021 \quad$ Online Published: October 19, 2021

doi:10.5539/ijsp.v10n6p22 URL: https://doi.org/10.5539/ijsp.v10n6p22

\begin{abstract}
Many authors have proposed measures for between groups income inequalities. Mostly, these measures are based on functional of the income distribution. Others are based on Gini index, measures of entropies or additive functions. Butler and McDonald (1987) developed a class of between groups income inequality measures based on incomplete moments and showed its applicability. In this article, A unified class of interdistributional inequality measures are introduced. Most of previous measures are special cases from the new class, such as Butler-McDonald measures. These new measures are estimated and studied. Also, the new general class is based on probability weighted moments which can be given any values as the upper value. A real data application is presented to compare among all these measures and show the benefits of the new measures.
\end{abstract}

Keywords: income inequality measures, interdistributional inequality measures, probability weighted moments, asymptotic normality, and simulation

\section{Introduction}

Butler and McDonald (1987) conferred four interdistributional Lorenz curves based on normalized incomplete moments. Also, they outlined Lorenz curve, Gini, and pietra measures of inequality across two populations.

The $h^{\text {th }}$ partial moment given by $y<x$ for density function $\mathrm{f}(y)$ is defined as

$$
I(x ; h)=\int_{0}^{x} y^{h} f(y) d y=\frac{\int_{0}^{x} y^{h} f(y) d y}{E\left(y^{h}\right)}=\frac{I(x ; h)}{E\left(y^{h}\right)}
$$

They referred to as the normalized incomplete moment that represents the proportion of each respective moment that is accounted for by income levels less than $\mathrm{x}$

The Gini coefficient was introduced by them as a weighted average of incomplete moments.

$$
\text { Gini }=\int_{0}^{\infty}[(x / \mu) \emptyset(x ; 0)-\emptyset(x ; 1)] f(x) d x
$$

They used a Lorenz curve to look at the disparity between black and white income distributions see for example Akee at el (2019), Smith and Welch (1985), Bloome at el (2014), Kearney at el (2014), and Bollinger at el (2015).

\section{Probability Weighted Moments}

Let $X_{1}, X_{2}, \ldots, X_{n}$ be a random sample from a continuous distribution with density function $f(x)$, quantile function $x(F)=F^{-1}(x)=Q(F), 0<F<1$, cumulative distribution function $F(x)=F$, mean $\mu=E(X)$, and $\sigma$ is the standard deviation of the distribution. The probability weighted moments are a generalization of the usual moments of a probability distribution. The probability weighted moments of a random variable $X$ with distribution function $\mathrm{F}(x)=$ $\mathrm{P}(\mathrm{x} \leq x)$ are the quantities

$$
M_{p, r, s}=E\left[X^{p}\{F(X)\}^{r}\{1-F(X)\}^{s}\right]
$$

where $p, r$ and $S$ are real numbers. PWM are likely the most useful when the quantile function $x(F)$ can be written in closed form, so we can rewrite 


$$
M_{p, r, s}=\int_{0}^{1}[x(F)]^{p} F^{r}(1-F)^{s} d F
$$

The quantities $M_{p, 0,0}$ are the usual non-central moments. When $r$ and $s$ are integers, $F^{r}(1-F)^{s}$ may be expressed as a linear combination of either powers of $F$ or powers of $(1-F)$, so it is natural to summarize a distribution either by the moments $M_{1, r, 0}$ or $M_{1,0, s}$, where

$$
\beta_{r}=M_{1, r, 0}=E\left[X\{F(X)\}^{r}\right], \quad r=0,1,2, \ldots
$$

and

$$
\beta_{s}=M_{1,0, s}=E\left[X\{1-F(X)\}^{s}\right], \quad s=0,1,2, \ldots
$$

where the expected value of order statistics is

$$
E\left(X_{r: n}\right)=\frac{n !}{(r-1) !(n-r) !} \int_{0}^{1} x(F) F^{r-1}(1-F)^{n-r} d F
$$

Therefore, PWM can be written in terms of expected value of order statistics as

$$
\beta_{r}=\int_{0}^{1} x(F) F^{r} d F=\frac{E\left(X_{r+1: r+1}\right)}{r+1}, \quad r=0,1, \ldots
$$

and

$$
\beta_{s}=\int_{0}^{1} x(F)(1-F)^{s} d F=\frac{E\left(X_{1: s+1}\right)}{s+1}, \quad s=0,1, \ldots
$$

Note that $\beta_{r}$ and $\beta_{s}$ are used in many; see for example, Abouelmagd, and Ahmed (2015), Bartolucci et al (1999), Greenwood et al (1979), Wei et al (2019), Hosking (1990), Hosking et al (1985), Basso et al (2016) and Moisello (2007).

\section{A Unified General Class of Interdistributional Income Inequality Measures Using PWM}

A proposed class of inequality measures which is a generalization of Butler-McDonald measure is

$$
\begin{gathered}
M_{P W M}^{(h, r, s)}=\frac{\int_{0}^{y_{*}}\left[x^{h}\{F(x)\}^{r}\{1-F(x)\}^{s}\right] d F(x)}{\int_{0}^{1}\left[x^{h}\{F(x)\}^{r}\{1-F(x)\}^{s}\right] d F(x)}-\frac{\int_{0}^{x_{*}}\left[y^{h}\{F(y)\}^{r}\{1-F(y)\}^{s}\right] d F(y)}{\int_{0}^{1}\left[y^{h}\{F(y)\}^{r}\{1-F(y)\}^{s}\right] d F(y)} \\
M_{P W M}^{(h, r, s)}=\phi\left(y_{*} ; h, r, s\right)-\phi\left(x_{*} ; h, r, s\right)
\end{gathered}
$$

This can be called "interdistributional normalized weighted incomplete moment".

\subsection{Measures Based on $\beta_{r}$}

We propose first version of measure of inequality based on PWM. This version will give more weight for income in the largest part of the distribution

$$
M_{G B M 1}^{(r, s)}=\left(\mu_{G X}^{(r, s)}\right)^{-1} \int_{0}^{\mu_{Y}^{r, s}}\left[x^{r}\{F(x)\}^{s}\right] d F(x)-\left(\mu_{G Y}^{(r, s)}\right)^{-1} \int_{0}^{\mu_{X}^{(r, s)}}\left[y^{r}\{F(y)\}^{s}\right] d G(y)
$$

$M_{G B M 1}^{(r, s)}$ can be explained as the difference between the proportion of the first population with total weighted income accounted for by those with weighted income less than $\mu_{Y}^{r, s}$ and the proportion of the second population with total weighted income accounted for by those with weighted income less than $\mu_{X}^{(r, s)}$.

\section{Special cases}

1-when $\mathrm{r}=0$ and $\mathrm{s}=0$

$$
M_{G B M 1}^{(0,0)}=\left(\mu_{G X}^{(0,0)}\right)^{-1} \int_{0}^{\mu_{G Y}^{o, 0}}\left[x^{o}\{F(x)\}^{0}\right] d F(x)-\left(\mu_{G Y}^{(0,0)}\right)^{-1} \int_{0}^{\mu_{G X}^{(0,0)}}\left[y^{0}\{F(y)\}^{0}\right] d G(y)
$$

$M_{G B M 1}^{(0,0)}$ can be explained as the difference between the fraction of the first population with income less than the mean of the second population and the fraction of the second population with income less than the mean of the first population.

2-when $\mathrm{r}=1$ and $\mathrm{s}=0$ 


$$
M_{G B M 1}^{(1,0)}=\left(\mu_{G X}^{(1,0)}\right)^{-1} \int_{0}^{\mu_{G Y}^{1,0}}\left[x^{1}\{F(x)\}^{0}\right] d F(x)-\left(\mu_{G Y}^{(1,0)}\right)^{-1} \int_{0}^{\mu_{G X}^{(1,0)}}\left[y^{1}\{F(y)\}^{0}\right] d G(y)
$$

This is Butler-McDonald measure when $\mathrm{r}=1 . M_{G B M 1}^{(1,0)}$ can be explained as the difference between the fraction of the first population with total income accounted for by those with total income less than the mean income of second population and the fraction of the second population with total income accounted for by those with total income less than the mean income of first population.

3-when $\mathrm{r}=0$ and $\mathrm{s}=1$

$$
\begin{gathered}
M_{G B M 1}^{(0,1)}=\left(\mu_{G X}^{(0,1)}\right)^{-1} \int_{0}^{\mu_{G Y}^{0,1}}\left[x^{0}\{F(x)\}^{1}\right] d F(x)-\left(\mu_{G Y}^{(0,1)}\right)^{-1} \int_{0}^{\mu_{G X}^{(0,1)}}\left[y^{0}\{F(y)\}^{1}\right] d G(y) . \\
M_{G B M 1}^{(0,1)}=\left(\mu_{G X}^{(0,1)}\right)^{-1} \int_{0}^{\mu_{G Y}^{0,1}} F(x) d F-\left(\mu_{G Y}^{(0,1)}\right)^{-1} \int_{0}^{\mu_{G X}^{(0,1)}} F(y) d G
\end{gathered}
$$

4-when $\mathrm{r}=1$ and $\mathrm{s}=1$

$$
\begin{gathered}
M_{G B M 1}^{(1,1)}=\left(\mu_{G X}^{(1,1)}\right)^{-1} \int_{0}^{\mu_{G Y}^{1,1}}\left[x^{1}\{F(x)\}^{1}\right] d F(x)-\left(\mu_{G Y}^{(1,1)}\right)^{-1} \int_{0}^{\mu_{G X}^{(1,1)}}\left[y^{1}\{F(y)\}^{1}\right] d G(y) \\
\mathrm{M}_{\mathrm{GBM} 1}^{(1,1)}=\left(\mu_{\mathrm{GX}}^{(1,1)}\right)^{-1} \int_{0}^{\mu_{\mathrm{GY}}^{1,1}} \mathrm{xF}(\mathrm{x}) \mathrm{dF}-\left(\mu_{\mathrm{GY}}^{(1,1)}\right)^{-1} \int_{0}^{\mu_{\mathrm{GX}}^{(1,1)}} \mathrm{y} \mathrm{F}(\mathrm{y}) \mathrm{dF}
\end{gathered}
$$

$\mathrm{M}_{\mathrm{GBM} 1}^{(1,1)}$ can be explained as the difference between the fraction of the first population with total weighted income accounted for by those with total weighted income less than the mean income of second population and the fraction of the second population with total weighted income accounted for by those with total weighted income less than the mean income of first population.

\subsection{Measures Based on $\boldsymbol{\beta}_{\boldsymbol{s}}$}

We propose second version of measure of inequality based on PWM. This version will give more weight for income in the lowest part of the distribution

$$
\mathrm{M}_{\mathrm{GBM} 2}^{(\mathrm{r}, \mathrm{s})}=\left(\mu_{\mathrm{GX}}^{(\mathrm{r}, \mathrm{s})}\right)^{-1} \int_{0}^{\mu_{\mathrm{Y}}^{\mathrm{r}, \mathrm{s}}}\left[\mathrm{x}^{\mathrm{r}}\{1-\mathrm{F}(\mathrm{x})\}^{\mathrm{s}}\right] \mathrm{dF}(\mathrm{x})-\left(\mu_{\mathrm{GY}}^{(\mathrm{r}, \mathrm{s})}\right)^{-1} \int_{0}^{\mu_{\mathrm{X}}^{(\mathrm{r}, \mathrm{s})}}\left[\mathrm{y}^{\mathrm{r}}\{1-\mathrm{F}(\mathrm{y})\}^{\mathrm{s}}\right] \mathrm{dG}(\mathrm{y})
$$

\section{Special cases}

1 -when $\mathrm{r}=0$ and $\mathrm{s}=0$

$$
M_{G B M 2}^{(0,0)}=\left(\mu_{G X}^{(0,0)}\right)^{-1} \int_{0}^{\mu_{G Y}^{0,0}}\left[x^{0}\{1-F(x)\}^{0}\right] d F(x)-\left(\mu_{G Y}^{(0,0)}\right)^{-1} \int_{0}^{\mu_{G X}^{(0,0)}}\left[y^{0}\{1-F(y)\}^{0}\right] d G(y)
$$

2-when $\mathrm{r}=1$ and $\mathrm{s}=0$

$$
M_{G B M 2}^{(1,0)}=\left(\mu_{G X}^{(1,0)}\right)^{-1} \int_{0}^{\mu_{G Y}^{1,0}}\left[x^{1}\{1-F(x)\}^{0}\right] d F(x)-\left(\mu_{G Y}^{(1,0)}\right)^{-1} \int_{0}^{\mu_{G X}^{(1,0)}}\left[y^{1}\{1-F(y)\}^{0}\right] d G(y)
$$

This is Butler-McDonald measure

3-when $\mathrm{r}=0$ and $\mathrm{s}=1$

$$
\begin{gathered}
M_{G B M 2}^{(0,1)}=\left(\mu_{G X}^{(0,1)}\right)^{-1} \int_{0}^{\mu_{G Y}^{0,1}}\left[x^{0}\{1-F(x)\}^{1}\right] d F(x)-\left(\mu_{G Y}^{(0,1)}\right)^{-1} \int_{0}^{\mu_{G X}^{(0,1)}}\left[y^{0}\{1-F(y)\}^{1}\right] d G(y) \\
M_{G B M 2}^{(0,1)}=\left(\mu_{G X}^{(0,1)}\right)^{-1} \int_{0}^{\mu_{G Y}^{0,1}}\{1-F(x)\} d F-\left(\mu_{G Y}^{(0,1)}\right)^{-1} \int_{0}^{\mu_{G X}^{(0,1)}}\{1-F(y)\} d G
\end{gathered}
$$

4-when $\mathrm{r}=1$ and $\mathrm{s}=1$ 


$$
\begin{gathered}
M_{G B M}^{(1,1)}=\left(\mu_{G X}^{(1,1)}\right)^{-1} \int_{0}^{\mu_{G Y}^{1,1}}\left[x^{1}\{1-F(x)\}^{1}\right] d F(x)-\left(\mu_{G Y}^{(1,1)}\right)^{-1} \int_{0}^{\mu_{G X}^{(1,1)}}\left[y^{1}\{1-F(y)\}^{1}\right] d G(y) \\
M_{G B M 2}^{(1,1)}=\left(\mu_{G X}^{(1,1)}\right)^{-1} \int_{0}^{\mu_{G Y}^{1,1}} x\{1-F(x)\} d F-\left(\mu_{G Y}^{(1,1)}\right)^{-1} \int_{0}^{\mu_{G X}^{(1,1)}} y\{1-F(y)\} d G
\end{gathered}
$$

\section{Estimation}

Using the sample income data $x_{1}, x_{2}, \ldots, x_{n}$ and the empirical distribution function the above measures can be estimated as follows.

4.1 Measures Based on $\boldsymbol{\beta}_{r}$

$$
\widehat{M}_{G B M}^{(r, s)}=\frac{\sum_{i=1}^{n} I\left(w_{r i} x_{i}^{r}<\bar{y}_{r}\right) w_{r i} x_{i}^{r}}{\sum_{i=1}^{n} w_{r i} x_{i}^{r}}-\frac{\sum_{i=1}^{n} I\left(w_{r i} y_{i}^{r}<\bar{x}_{r}\right) w_{r i} y_{i}^{r}}{\sum_{i=1}^{n} w_{r i} y_{i}^{r}}
$$

and

$$
\widehat{M}_{G A}^{(r, s)}=\frac{\sum_{i=1}^{n} I\left(w_{r r} x_{i}^{r}<\bar{y}_{r}\right) w_{r i} x_{i}^{r}}{\hat{F}\left(\bar{y}_{r}\right)}-\frac{\sum_{i=1}^{n} I\left(w_{r i} y_{i}^{r}<\bar{x}_{r}\right) w_{r i} y_{i}^{r}}{\hat{F}\left(\bar{x}_{r}\right)}
$$

Where $\hat{F}$ is the empirical distribution function and

4.2 Measures Based on $\beta_{s}$

$$
w_{r i}=\left(\frac{i-0.5}{n}\right)^{r}
$$

$$
\begin{aligned}
& \widehat{M}_{G B M}^{(r, s)}=\frac{\sum_{i=1}^{n} I\left(w_{s i} x_{i}^{r}<\bar{y}_{s}\right) w_{s i} x_{i}^{r}}{\sum_{i=1}^{n} w_{s i} x_{i}^{r}}-\frac{\sum_{i=1}^{n} I\left(w_{s i} y_{i}^{r}<\bar{x}_{S}\right) w_{s i} y_{i}^{r}}{\sum_{i=1}^{n} w_{s i} y_{i}^{r}} \\
& \widehat{M}_{G A}^{(r, s)}=\frac{\sum_{i=1}^{n} I\left(w_{s i} x_{i}^{r}<\bar{y}_{s}\right) w_{s i} x_{i}^{r}}{\hat{F}^{r}\left(\bar{y}_{s}\right)}-\frac{\sum_{i=1}^{n} I\left(w_{s i} y_{i}^{r}<\bar{x}_{s}\right) w_{s i} y_{i}^{r}}{\left.\hat{F}_{(} \bar{x}_{s}\right)}
\end{aligned}
$$

Where

\section{Applications}

$$
w_{s i}=\left(1-\frac{(i-0.5)}{n}\right)^{s}
$$

\subsection{Theoretical Application}

If $X_{1}, X_{2}, \ldots \ldots, X_{n}$ from pareto distribution with density function $_{1} d f=a k^{a} x^{-(a+1)}$, cumulative distribution function $F=1-\left(\frac{k}{x}\right)$, quantile function $\mathrm{X}(\mathrm{F})=\mathrm{k}(1-F)^{\frac{-1}{a}}, r^{t h}$ noncertral moments $\quad \grave{r}=a k^{r}(a-r)^{-1}$ and

$\mu_{G X}^{(r, s)}=\int_{0}^{\infty} x^{r} F^{s} d F, \mu_{G Y}^{(r, s)}=\int_{0}^{\infty} y^{r} F^{s} d G$, then we can drive

\section{a. Measures based on $\beta_{r}$}

$$
M_{G B M}^{(r, s)}=\left(\mu_{G X}^{(r, s)}\right)^{-1} \int_{0}^{\mu_{Y}^{r, s}}\left[x^{r}\{F(x)\}^{s}\right] d F(x)-\left(\mu_{G Y}^{(r, s)}\right)^{-1} \int_{0}^{\mu_{X}^{(r, s)}}\left[y^{r}\{F(y)\}^{s}\right] d G(y) .
$$

which when using the indicator function gives

$$
M_{G B M}^{(r, s)}=\frac{1}{\int_{0}^{1} x^{r} F^{s} d F} \int_{0}^{\infty} I\left(x \leq \mu_{G y}^{(r, s)}\right) x^{r} F^{s} d F-\frac{1}{\int_{0}^{1} y^{r} F^{s} d G} \int_{0}^{\infty} I\left(y \leq \mu_{G x}^{(r, s)}\right) y^{r} F^{s} d G
$$

Or equivalently,

$$
M_{G B M}^{(r, s)}=\frac{1}{\int_{0}^{1}(x(F))^{r} F^{s} d F} \int_{0}^{\infty} I\left(x \leq \mu_{G y}^{(r, s)}\right)(x(F))^{r} F^{s} d F-\frac{1}{\int_{0}^{1}(y(F))^{r} F^{s} d G} \int_{0}^{\infty} I\left(y \leq \mu_{G x}^{(r, s)}\right)(y(F))^{r} F^{s} d G
$$




$$
\begin{aligned}
& \left.M_{G B M}^{(r, s)}=\frac{1}{\int_{0}^{1}\left((1-F)^{\frac{-1}{a_{1}}}\right)^{r} F^{s} d G} \int_{0}^{\infty} I\left(k_{1}(1-F)^{\frac{-1}{a_{1}}}\right) \leq \mu_{G y}^{(r, s)}\right)\left((1-F)^{\frac{-1}{a_{1}}}\right)^{r} F^{s} d F \\
& \left.-\frac{1}{\int_{0}^{1}\left((1-F)^{\frac{-1}{a_{2}}}\right)^{r} F^{s} d G} \int_{0}^{\infty} I\left(k_{2}(1-F)^{\frac{-1}{a_{2}}}\right) \leq \mu_{G x}^{(r, s)}\right)\left((1-F)^{\frac{-1}{a_{2}}}\right)^{r} F^{s} d G
\end{aligned}
$$

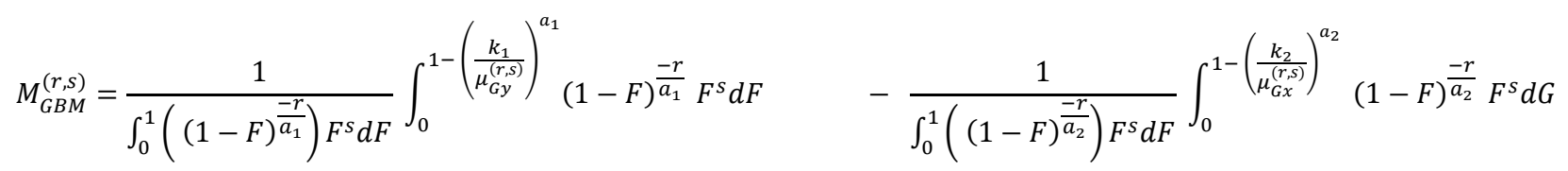

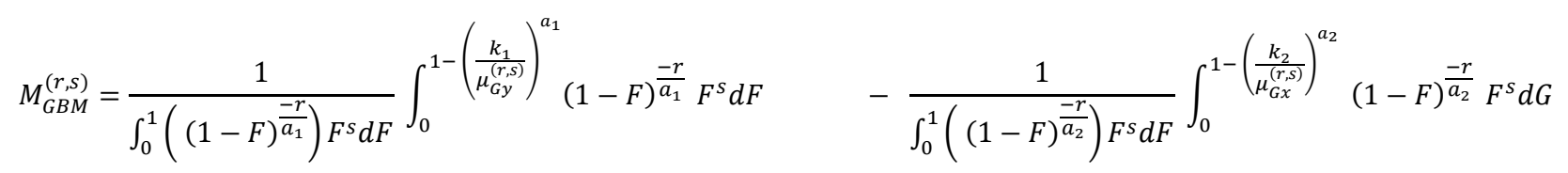

And by using Karl Pearson's incomplete beta function. We find

$$
M_{G B M}^{(r, s)}=\frac{\mathrm{I}\left(\frac{-r}{a_{1}}+1, s+1 ;\left(1-\left(\frac{k_{1}}{\beta\left(\frac{-r}{a_{1}}+1, s+1\right)}\right)^{a_{1}}\right)\right)}{\beta\left(\frac{-r}{a_{1}}+1, s+1\right)}-\frac{\mathrm{I}\left(\frac{-r}{a_{2}}+1, s+1 ;\left(1-\left(\frac{k_{2}}{\beta\left(\frac{-r}{a_{2}}+1, s+1\right)}\right)^{a_{2}}\right)\right)}{\beta\left(\frac{-r}{a_{2}}+1, s+1\right)}
$$

\section{b. Measures Based on $\beta_{\text {s }}$}

$$
M_{G B M}^{(r, s)}=\left(\mu_{G X}^{(r, s)}\right)^{-1} \int_{0}^{\mu_{Y}^{r, s}}\left[x^{r}\{1-F(x)\}^{s}\right] d F(x)-\left(\mu_{G Y}^{(r, s)}\right)^{-1} \int_{0}^{\mu_{X}^{(r, s)}}\left[y^{r}\{1-F(y)\}^{s}\right] d G(y) .
$$

which when using the indicator function gives:

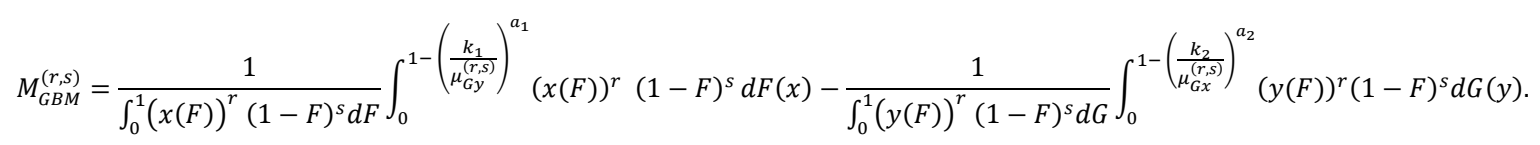

Or equivalently,

$$
\begin{aligned}
& M_{G B M}^{(r, s)}=\frac{1}{\int_{0}^{1}\left(k_{1}(1-F)^{\frac{-1}{a_{1}}}\right)^{r}(1-F)^{s} d F} \int_{0}^{1-\left(\frac{k_{1}}{\mu_{G y}^{(r, s)}}\right)^{a_{1}}}\left(k_{1}(1-F)^{\frac{-1}{a_{1}}}\right)^{r}(1-F)^{s} d F(x) \\
& -\frac{1}{\int_{0}^{1}\left(k_{2}(1-F)^{\frac{-1}{a_{2}}}\right)^{r}(1-F)^{s} d G} \int_{0}^{1-\left(\frac{k_{2}}{\mu_{G x}^{(r, s)}}\right)^{a_{2}}}\left(k_{2}(1-F)^{\frac{-1}{a_{2}}}\right)^{r}(1-F)^{s} d G(y) . \\
& M_{G B M}^{(r, s)}=\frac{1}{\int_{0}^{1}(1-F)^{\frac{-r}{a_{1}}+s} d F} \int_{0}^{1-\left(\frac{k_{1}}{\mu_{G y}^{(r, s)}}\right)^{a_{1}}}(1-F)^{\frac{-r}{a_{1}}+s} d F(x)-\frac{1}{\int_{0}^{1}(1-F)^{\frac{-r}{a_{2}}+s} d G} \int_{0}^{1-\left(\frac{k_{2}}{\mu_{G x}^{(r, s)}}\right)^{a_{2}}}(1-F)^{\frac{-r}{a_{2}}+s} d G
\end{aligned}
$$

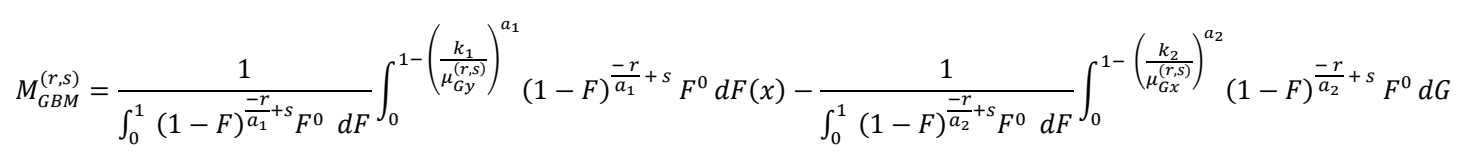




$$
M_{G B M}^{(r, s)}=\frac{I\left(\frac{-r}{a_{1}}+s+1,1 ;\left(1-\left(\frac{k_{1}}{\beta\left(\frac{-r}{a_{1}}+s+1,1\right)}\right)^{a_{1}}\right)\right)}{\beta\left(\frac{-r}{a_{1}}+s+1,1\right)}-\frac{I\left(\frac{-r}{a_{2}}+s+1,1 ;\left(1-\left(\frac{k_{2}}{\beta\left(\frac{-r}{a_{2}}+s+1,1\right)}\right)^{a_{2}}\right)\right)}{\beta\left(\frac{-r}{a_{2}}+s+1,1\right)}
$$

\section{c. Butler-McDonald}

$$
\begin{aligned}
& M_{B M}^{r}=\frac{1}{\int_{0}^{1} x^{r} d F} \int_{0}^{\mu_{Y}^{(r)}} x^{r} d F(x)-\frac{1}{\int_{0}^{1} y^{r} d G} \int_{0}^{\mu_{X}^{(r)}} y^{r} d F(y)=\phi_{X}\left(r, \mu_{Y}^{(r)}\right)-\phi_{Y}\left(r, \mu_{X}^{(r)}\right) \\
& M_{B M}^{r}=\frac{1}{\int_{0}^{1}\left[k_{1}(1-F)^{\frac{-1}{a_{1}}}\right]^{r} d F} \int_{0}^{1-\left(\frac{k_{1}}{\mu_{y}^{(r)}}\right)^{a_{1}}}\left[k_{1}(1-F)^{\frac{-1}{a_{1}}}\right]^{r} d F(x)-\frac{1}{\int_{0}^{1}\left[k_{2}(1-F)^{\frac{-1}{a_{2}}}\right]^{r} d G} \int_{0}^{1-\left(\frac{k_{2}}{\mu_{x}^{(r)}}\right)^{a_{2}}}\left[k_{2}(1-F)^{\frac{-1}{a_{2}}}\right]^{r} d G(y)
\end{aligned}
$$

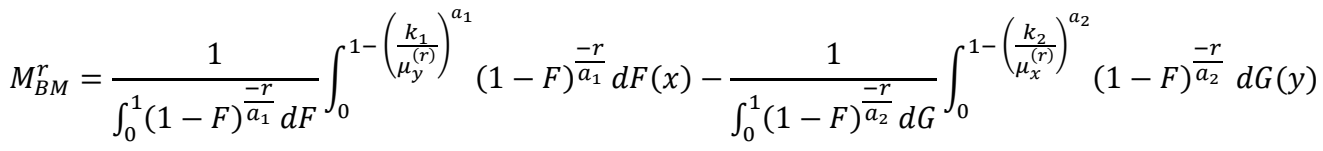

$$
\begin{aligned}
& M_{B M}^{r}=\frac{1}{\int_{0}^{1}(1-F)^{\frac{-r}{a_{1}}} F^{0} d F} \int_{0}^{1-\left(\frac{k_{1}}{\mu_{y}^{(r)}}\right)^{a_{1}}}(1-F)^{\frac{-r}{a_{1}}} F^{0} d F(x)-\frac{1}{\int_{0}^{1}(1-F)^{\frac{-r}{a_{2}}} F^{0} d G} \int_{0}^{1-\left(\frac{k_{2}}{\mu_{x}^{(r)}}\right)^{a_{2}}}(1-F)^{\frac{-r}{a_{2}}} F^{0} d G(y) \\
& M_{B M}^{r}=\frac{I\left(\frac{-r}{a_{1}}+1,1 ;\left(1-\left(\frac{k_{1}}{\beta\left(\frac{-r}{a_{1}}+1,1\right)}\right)^{a_{1}}\right)\right)}{\beta\left(\frac{-r}{a_{1}}+1,1\right)}-\frac{I\left(\frac{-r}{a_{2}}+1,1 ;\left(1-\left(\frac{k_{2}}{\beta\left(\frac{-r}{a_{2}}+1,1\right)}\right)^{a_{2}}\right)\right)}{\beta\left(\frac{-r}{a_{2}}+1,1\right)}
\end{aligned}
$$

\subsection{Real Data Application}

We will use real data to compute and compare Butler-MacDonald measure, and the proposed inequality measures. The income data is from the survey of national income and individuals' incomes in Egypt in 2009, and 2011, we consider the applicability to calculate and compare among income inequality indicators. The data set was obtained from the Central Agency for Public Mobilization and Statistics (CAPMS), which is responsible for systematically researching and analyzing incomes and consumptions of people every two years regularly. The CAPMS sample is a random sample from all Egyptian Governorates and the sample size is around 25000 units. The CAPMS gave us the data of incomes and consumptions of 12000 approximately individuals of the survey in the two years. Also, these data contain all details about incomes and consumptions of the individuals. For example, the individual income consists of salary and wages, agrarian income, and inherited income etc. Also, the individual consumption consists of the expenditure on cloths, food, and drinks etc.

In addition, we divided the whole country into Cairo, North, South, Canal, Delta sectors, and each of these sectors contain several governorates. For example, Cairo sector in 2009 contains Cairo, Giza, Helwan, and 6 Octorber, but in 2011 Cairo sector consists of Cairo, and Giza. The North sector contains Matruh, Alexanderia, Dumyat, Kafr Alshaykh, and Al Buhayrah and the South sector consists of Fayoum, Bani Suif, Menia, Asiut, Sohag, Qinal, luxor, Aswan, and El Wady Elgadeed. The sample from each sector we take for analysis in 2009 is 2000 individuals, while the sample in 2011 is 500 individuals for each sector.

The following tables will be calculated for the four years to Butler-McDonald measure $\left(M_{B M}^{r}\right)$, generalized Butler-MacDonald Measure based on $\beta_{r}\left(M_{P W M 1}^{r}\right)$, and generalized Butler-MacDonald measure based on $\beta_{s}\left(M_{P W M 2}^{r}\right)$. 
Table 1. Interdistributional income inequality between Cairo sector and North sector in 2009

\begin{tabular}{|l|c|c|c|}
\hline $\mathrm{r}$ & $\boldsymbol{M}_{\boldsymbol{B M}}^{\boldsymbol{r}}$ & $\boldsymbol{M}_{\boldsymbol{P W M 1}}^{r}$ & $\boldsymbol{M}_{\boldsymbol{P W M} \mathbf{2}}^{\boldsymbol{s}}$ \\
\hline 1 & -0.2009341 & -0.1492824 & -0.0516517 \\
2 & -0.3358347 & $-6.318484 \mathrm{e}-06$ & $-4.715487 \mathrm{e}-06$ \\
3 & -0.3745719 & $-1.438133 \mathrm{e}-10$ & $-1.348346 \mathrm{e}-10$ \\
4 & -0.2716791 & $-1.756166 \mathrm{e}-15$ & $-1.725486 \mathrm{e}-15$ \\
5 & -0.2373769 & $-1.530121 \mathrm{e}-20$ & $-1.455514 \mathrm{e}-20$ \\
\hline
\end{tabular}

Table 2. Interdistributional income inequality between Cairo sector and South sector in 2009

\begin{tabular}{|c|c|c|c|}
\hline $\mathrm{r}$ & $\boldsymbol{M}_{\boldsymbol{B M}}^{\boldsymbol{r}}$ & $\boldsymbol{M}_{\boldsymbol{P W M 1}}^{\boldsymbol{N}}$ & $\boldsymbol{M}_{\boldsymbol{P W M 2}}^{\boldsymbol{s}}$ \\
\hline 1 & -0.4762717 & -0.2953932 & -0.1808785 \\
2 & -0.5431033 & $-1.109482 \mathrm{e}-05$ & $-8.483327 \mathrm{e}-06$ \\
3 & -0.4067344 & $-2.056898 \mathrm{e}-10$ & $-1.900043 \mathrm{e}-10$ \\
4 & -0.1508454 & $-1.426814 \mathrm{e}-15$ & $-1.431211 \mathrm{e}-15$ \\
5 & -0.0422706 & $-5.972053 \mathrm{e}-21$ & $-6.133158 \mathrm{e}-21$ \\
\hline
\end{tabular}

A number of points are noteworthy from the results of tables 1 and 2:

1. At the first glance, in table 1, all signs are negative that means the inequality in North sector is higher than inequality in Cairo sector. In other words, the difference among incomes in North sector is higher than the difference among incomes in Cairo sector under the same economic conditions such inflation and policies.

2. In table 1 , the interdistributional income inequality has the range from -0.0516517 to -0.2009341 , when $r=1$. That means Butler-McDonald measure gives the highest interdistributional income inequality between Cairo sector and North sector, but the proposed $\beta_{s}$ measure gives the lowest interdistributional income inequality.

3. In table 1, the values of Butler-McDonald measure still have a useful meaning when $r^{\text {th }}$ increase, because these values can measure the interdistributional income inequality when $r=2$ to $r=5$. However, the values of the proposed $\beta_{r}$, and $\beta_{s}$ measures are approximately zero.

4. In table 2, all signs are negative that means the inequality in South sector is higher than inequality in Cairo sector. In other words, the difference among incomes in South sector is higher than the difference among incomes in Cairo sector under the same economic conditions such inflation and policies.

5. The results from table 2 bucks up the conclusion obtained from table 1 .

Table 3. Interdistributional income inequality between Cairo sector and North sector in 2011

\begin{tabular}{|c|c|c|c|}
\hline $\mathrm{r}$ & $\boldsymbol{M}_{\boldsymbol{B M}}^{\boldsymbol{r}}$ & $\boldsymbol{M}_{\boldsymbol{P W M 1}}^{\boldsymbol{1}}$ & $\boldsymbol{M}_{\boldsymbol{P W M 2}}^{\boldsymbol{S}}$ \\
\hline 1 & -0.290286 & -0.1982195 & -0.09206645 \\
2 & -0.3357666 & $-4.642237 \mathrm{e}-06$ & $-3.390301 \mathrm{e}-06$ \\
3 & -0.2422896 & $-5.029476 \mathrm{e}-11$ & $-5.147463 \mathrm{e}-11$ \\
4 & -0.1600472 & $-3.14515 \mathrm{e}-16$ & $-3.323548 \mathrm{e}-16$ \\
5 & -0.1149761 & $-1.596027 \mathrm{e}-21$ & $-1.565911 \mathrm{e}-21$ \\
\hline
\end{tabular}

Table 4. Interdistributional income inequality between Cairo sector and South sector in 2011

\begin{tabular}{|c|c|c|c|}
\hline $\mathrm{r}$ & $\boldsymbol{M}_{\boldsymbol{B M}}^{\boldsymbol{r}}$ & $\boldsymbol{M}_{\boldsymbol{P W M 1}}^{\boldsymbol{M}}$ & $\boldsymbol{M}_{\boldsymbol{P W M 2}}^{\boldsymbol{S}}$ \\
\hline 1 & -0.5809797 & -0.3415718 & -0.2394079 \\
2 & -0.6865492 & $-1.000246 \mathrm{e}-05$ & $-8.389739 \mathrm{e}-06$ \\
3 & -0.7954165 & $-2.125916 \mathrm{e}-10$ & $-2.038938 \mathrm{e}-10$ \\
4 & -0.9986064 & $-3.54929 \mathrm{e}-15$ & $-3.333598 \mathrm{e}-15$ \\
5 & -0.9998331 & $-4.556232 \mathrm{e}-20$ & $-4.253245 \mathrm{e}-20$ \\
\hline
\end{tabular}

A number of points are noteworthy from the results of tables 3 and 4:

6. All signs in tables 3 and 4 are negative that means the income inequality of the North sector is higher than the income inequality of the Cairo sector. Also, the income inequality of the South sector is higher than the income inequality of Cairo sector under the same economic and political conditions.

7. The interdistributional income inequality between Cairo sector and North sector raised from 2009 to 2011 . We can explain this by showing the figures of all measures in 2009 and the figures in 2011. For example, when we compare 
between table 1 and 3, when $\mathrm{r}$ equals 1 , and by using Butler-McDonald measure the interdistributional income inequality increased from -0.2009341 in 2009 to -0.290286 in 2011 , for $\beta_{r}$ measure the interdistributional income inequality rose from -0.1492824 in 2009 to -0.1982195 in 2011 , and for $\beta_{s}$ measure the interdistributional income inequality rose from -0.0516517 to -0.09206645

8. Also, the interdistributional income inequality between Cairo sector and South sector increased from 2009 to 2011. All values of all measures buck up this result for all values of $r^{t h}$.

\section{Conclusion}

Many public policies impact poor people. Furthermore, some policies are specifically designed to target the poor in order to fight poverty. In policy work it is therefore important to be able to identify the poor, to simulate the impact of alternative policies on poverty, and to rank policy options according to some poverty impact indicators in order to select the most preferred option.

Inequality measurement is an attempt to give meaning to comparisons of income distributions in terms of criteria which may be derived from ethical principles, appealing mathematical constructs or simple intuition.

In this research, we review the concepts of poverty, inequality, and social welfare. In addition, we discuss axioms of poverty and inequality measures and we review several measures of poverty, inequality, and social welfare to know the disadvantages of these measures to avoid them in our proposed measures.

In recent years the probability weighted method (PWM) plays an important role in parameter estimation of the distributions. The powerful of PWM is in its simplicity and efficient of the estimates in comparison with traditional method of moments and maximum likelihood method. However, Butler-McDonald (1989) and Ahmed (1998) introduced a measure of inequality which takes into consideration the shape of the distribution based on traditional non-central moments that is not efficient with respect to PWM.

Therefore new measure of inequality that takes in consideration the shape of the distribution based on PWM is proposed. Two versions of this measure are defined and studied. We study these new measures under Pareto distribution because Pareto distribution is the nearest distribution to income distribution. Moreover, it is shown that the main advantage of the proposed measure it characterizes the income distribution among all distributions.

A new measure of interdistributional inequality is proposed and two versions of this measure are defined and studied. Several cases of these two versions are derived and defined. We study these measures under Pareto distribution.

A real data application is given that illustrates the benefits of the proposed measures.

\section{References}

Abouelmagd, T., \& Ahmed, A. (2015). Comparison between Lorenz Curve and Butler-McDonald measure for income and consumption inequality. Journal of Statistics: Advances in Theory and Applications, 14(2), 221-234. https://doi.org/10.18642/jsata_7100121604

Akee, R., Jones, M. R., \& Porter, S. R. (2019). Race matters: Income shares, income inequality, and income mobility for all US races. Demography, 56(3), 999-1021. https://doi.org/10.1007/s13524-019-00773-7

Bartolucci, A. A., Singh, K. P., Bartolucci, A. D., \& Bae, S. (1999). Applying medical survival data to estimate the three-parameter Weibull distribution by the method of probability-weighted moments. Mathematics and computers in simulation, 48(4-6), 385-392. https://doi.org/10.1016/S0378-4754(99)00018-X

Basso, S., Schirmer, M., \& Botter, G. (2016). A physically based analytical model of flood frequency curves. Geophysical Research Letters, 43(17), 9070-9076. https://doi.org/10.1002/2016GL069915

Bloome, D. (2014). Racial inequality trends and the intergenerational persistence of income and family structure. American sociological review, 79(6), 1196-1225. https://doi.org/10.1177/0003122414554947

Bollinger, C. R., Hirsch, B. T., Hokayem, C., \& Ziliak, J. P. (2015). Measuring levels and trends in earnings inequality with nonresponse, imputations, and topcoding. In Submitted for presentation at the Society of Labor Economists meetings, Montreal, June (pp. 26-28).

Butler, R. J., \& McDonald, J. B. (1987). Interdistributional income inequality. Journal of Business \& Economic Statistics, 5(1), 13-18. https://doi.org/10.1080/07350015.1987.10509555

Greenwood, J. A., Landwehr, J. M., Matalas, N. C., \& Wallis, J. R. (1979). Probability weighted moments: definition and relation to parameters of several distributions expressable in inverse form. Water resources research, 15(5), 1049-1054. https://doi.org/10.1029/WR015i005p01049

Hosking, J. R. M., Wallis, J. R., \& Wood, E. F. (1985). Estimation of the generalized extreme-value distribution by the 
method of probability-weighted moments. $\quad$ Technometrics, $27(3), \quad$ 251-261. https://doi.org/10.1080/00401706.1985.10488049

Hosking, J. R. (1990). L-moments: Analysis and estimation of distributions using linear combinations of order statistics. Journal of the Royal Statistical Society: Series B (Methodological), 52(1), 105-124.

Kearney, M. S., \& Levine, P. B. (2014). Income inequality, social mobility, and the decision to drop out of high school (No. w20195). National Bureau of Economic Research. https://doi.org/10.3386/w20195

Moisello, U. (2007). On the use of partial probability weighted moments in the analysis of hydrological extremes. Hydrological Processes: An International Journal, 21(10), 1265-1279. https://doi.org/10.1002/hyp.6310

Smith, J. P., \& Welch, F. R. (1985). Racial Discrimination: A Human Capital Perspective. Three Worlds of Labor Economics, 1960-1970.

Wei, T., \& Song, S. (2019). Probability Weighted Moments-Based Parameter Estimation for Kinematic Diffusion and Muskingum-Based Distributions. Journal of Hydrologic Engineering, 24(12), 04019054. https://doi.org/10.1061/(ASCE)HE.1943-5584.0001863

\section{Copyrights}

Copyright for this article is retained by the author(s), with first publication rights granted to the journal.

This is an open-access article distributed under the terms and conditions of the Creative Commons Attribution license (http://creativecommons.org/licenses/by/4.0/). 